\title{
Estimation of daily intake distribution of flavonols and flavanones in Denmark
}

\author{
By Ulla Justesen, Pia Knuthsen, Niels Lyhne Andersen and Torben Leth \\ Received: August 28; Revised: November 9; Accepted: November 28, 2000
}

\begin{abstract}
Flavonoids are a part of the large group of polyphenols, and they are found in tea, fruit, vegetables, and red wine. The daily flavonoid (flavonols and flavanones) intake in Denmark was calculated based on consumption and analysis of flavonoid contents of foods on the Danish market. Orange, tea, onions, and orange juice were found to provide the greatest contributions to the total flavonoid intake, whereas green vegetables made minor contributions to the intake. Gender differences in flavonoid intake were observed, a lower mean flavonol and flavanone consumption was calculated for men $(20 \mathrm{mg} /$ day $)$ than for women $(26 \mathrm{mg} /$ day $)$. The gender difference could be almost solely explained by the differences in consumption of tea and oranges. It will, however, be relevant to consider a total estimate of flavonoids (flavones, flavonols, flavanones, procyanidins, and anthocyanidins), as well as other natural antioxidants, to evaluate the health effects of foods.

Key words: Flavonoids, fruit and vegetables, gender differences, intake, tea
\end{abstract}

\section{Introduction}

There is much interest in plant polyphenols, as it has been shown that high intakes of fruit and vegetables have protective effect against stroke and heart diseases (1-3) as well as cancer (2,4). Rich sources of polyphenols are tea, wine, fruits and vegetables (5-7). Tea consumption has been shown protective to digestive and urinary tract cancers (8) in addition to beneficial effects on atherosclerosis (9). Epidemiological studies have been performed to investigate the relationship between dietary intakes of individual polyphenolic compounds, and the risk of heart diseases and cancers. Dietary intakes of flavonoids have been negatively associated with the incidence of heart diseases (9-12) and dementia (13). It has not been possible, until recently, in epidemiological studies, to verify any significant negative association of a single nutrient group as flavonoids and cancer risks $(2,14)$ even though flavonoids have been proved to be strong in vitro and in vivo antioxidants (15). However, a recent study found intake of one flavonol, kaempferol, to be protective to gastric cancer in Spain (16).

The most common flavonoids in foods are the flavonols, flavones, flavanones (figure 1), catechins, and anthocyanidins. They are widely distributed and exist mainly as O-glycosides where one or more

Ulla Justesen, Ph.D., Pia Knuthsen*, Senior Research Chemist, Niels Lyhne Andersen, Senior Research Nutritionist, Torben Leth, Head of Dept., Institute of Food Research and Nutrition, Danish Veterinary and Food Administration, Mørkhøj

Bygade 19, DK-2860 Søborg, Denmark.

* Correspondence. E-mail pk@fdir.dk of the hydroxyl groups are bound to sugar units (17). It is not firmly established in which form (glycosides or aglycones) the flavonoids are absorbed in the gut system. It has been shown that absorption can occur in the ileum (18), and a recent paper from the same research group suggests that the bioavailability is in part dependent on the glycosyl conjugate (19). The major part of the flavonoids is still expected to reach the colon, where it is subject to bacterial degradation $(2,20,21)$. In feeding studies, only a minor fraction of the ingested quercetin has been detected as urinary excretion product $(19,22,23)$, whereas a much higher proportion of ingested isorhamnetin (22) and flavanones in citrus products (24) have been recovered in urine. The bioavailability may thus be dependent on the aglycone nature as well as the glycosyl conjugate.

Based on the potential beneficial effects of flavonoids in the diet, it is of great interest to estimate the dietary intake of flavonoids. A number of reports on dietary intake of flavonoids, based on compositional data of foods, have been published so far $(11,13,16,25-28)$, most studies reporting the intake of flavones and flavonols. Total flavonol and flavone intake ranged from 3 to $65 \mathrm{mg} /$ day, lowest in Finland ( $3 \mathrm{mg} /$ day) and highest in Japan $(65 \mathrm{mg} /$ day), quercetin accounting for the majority of the intake.

The present study estimates the intake of flavonoids (flavonols and flavanones) in Denmark, based on analytical data of foods available on the Danish market (6) and consumption of the individual foods (29). We found that flavones contributed virtually nothing to the mean flavonoid consumption; instead, we included flavanones as they provide a major contribution.

We have previously presented preliminary data on flavonoid intake in Denmark (30), covering only a part of the food composition data in the present study (e.g. not including red wine) and estimating food consumption from household consumption data from 1987 . The use of dietary records in the present study allows a more accurate measurement of food consumption and also determination of gender differences in flavonoid intake.

\section{Methods}

\section{Food consumption}

Calculation of consumption of the individual foods was based on the Dietary Habits in Denmark 1995 (29). The nation-

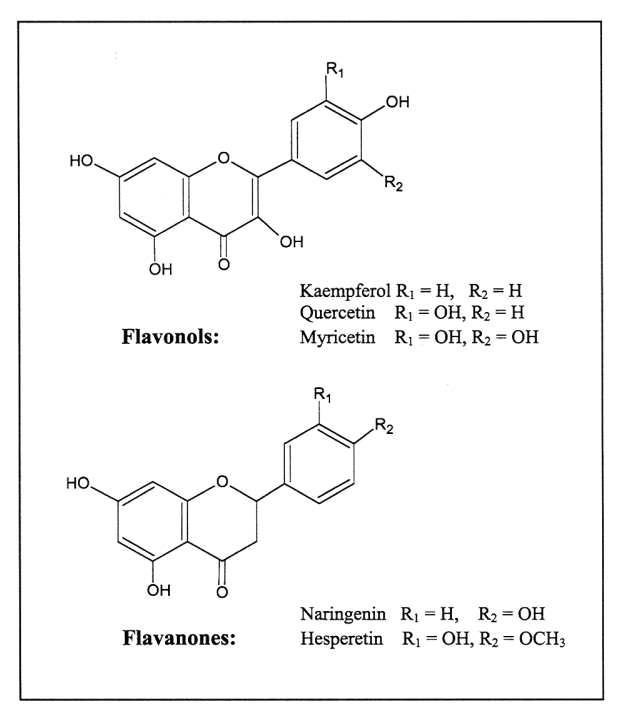

Figure 1. Structures of flavonols and flavanones. 

aged 1-80 years. The dietary records of 933 female and 904 male participants aged 15-80 years were used for calculating intakes of flavonoids. Dietary data were self-recorded for seven consecutive days in booklets with pre-printed fixed answering categories supplemented with open categories covering 210 individual food items. The quantity of food eaten was estimated from household measures and four different series of pictures. The survey population was a random sample drawn from the Central Population Register, stratified by sex and age. The total response rate was $58 \%$ for adults. Data were collected in three periods of 1995: January-February, April-May and AugustSeptember, to account for seasonal variations of the diet.

\section{Determination of flavonoids}

Determination of flavonoids in foods was performed as described in (6). Briefly, a wide range of food samples were purchased at local grocery stores, rinsed, divided in edible and non-edible parts, freeze-dried and kept at $-18^{\circ} \mathrm{C}$. Different varieties were purchased of each sample type over a 2 -year period. The red wines were produced throughout the world, and from different years (1989-1995). Black and green bulk and bagged teas were used, and brewed as indicated by the manufacturer. The freeze-dried food samples and the liquid samples were acid-hydrolysed prior to HPLC separation and the flavonoids determined as aglycones by diode-array detection. The peak areas were used for calculation of the contents in the samples. The data reported for onion are for yellow onion as the intake of other varieties (red and spring onion) is limited. Quantifiable levels (>0.1 mg/100g fresh weight sample) of quercetin, kaempferol, hesperetin, naringenin, myricetin, apigenin, and luteolin were found in 38 food subjects. Flavonoid intake was calculated by multiplying the individual consumption of each food by the mean flavonoid content in the food samples and the wide survey included 3098 participants products were summarized for each individual participant. The five flavonols and flavanones presented in Figure 1 were found to be significant contributors to the flavonoid intake. Mean and percentiles of the intake distributions were calculated. In the nation-wide survey questionnaire, apple and pear were not distinguished, so the value of apple consumption in Table 1 includes the pear consumption as well. This is not likely to introduce a significant error in flavonoid intake, since the apple consumption is considerably higher than the pear consumption and the flavonoid contents of whole apple and pear are at comparable levels. Likewise, tangerines (with flavanone contents similar to those found in oranges) were included in the orange consumption value in Table 1.

\section{Results}

A number of fruit, vegetables, and beverages were found to contain flavones, flavonols, and flavanones (6). Table 1 lists the mean consumption (g/day) of the foods with major contributions to flavonoid intake. The mean daily intake of flavonols and flavanones was estimated to $23 \mathrm{mg} / \mathrm{day}$ (median $16 \mathrm{mg} / \mathrm{d}$ ), as shown in Table 2 . The main food contributors were oranges, tea, onions, orange juice, red wine, apples and tomatoes (Table 1). Vegetables other than onions were found to provide $1 \%$ or less of the total flavonoid intake. Quercetin was found to be most widely distributed, and to comprise, as single component, the major part (37\%) of the mean flavonoid intake (Table 2). Citrus fruit contain high levels of the flavanones naringenin and hesperetin, and due to the high consumption of oranges and other citrus fruit, the contribution of flavanones was therefore found to be considerable $(40 \%)$. The intakes of apigenin, luteolin, isorhamnetin, and eriodictyol are negligible $(<0.1 \mathrm{mg} / \mathrm{d})$ and therefore not included in the results of the present study.

Table 3 illustrates the gender differences in mean and median values for flavonoid intake. The mean intake for all
Table 1. Mean consumption of the main food items that contribute to the flavonoid intake among men $n=904$ and women $n=933$ (total $n=1837$ ). Contributions of the individual foods to the flavonol and flavanone intake are presented as \% of the total mean intake $(=23 \mathrm{mg} / \mathrm{d})$.

\begin{tabular}{lcc}
\hline Food & $\begin{array}{c}\text { Consumption } \\
\text { g/day }\end{array}$ & $\begin{array}{c}\text { Contribution } \\
\%\end{array}$ \\
\hline Apple & 48 & 4 \\
Onion & 10 & 16 \\
Orange & $16^{1}$ & 30 \\
Orange juice & 23 & 10 \\
Red Wine & 67 & 5 \\
Tea & $200^{2}$ & 29 \\
Tomatoes & 16 & 2 \\
Other & - & 4 \\
\hline
\end{tabular}

For men and women: ${ }^{1}(13 ; 19) ;{ }^{2}(153 ; 245)$

participants was $23 \mathrm{mg} /$ day, mean values of $26 \mathrm{mg} /$ day for women and $20 \mathrm{mg} /$ day for men. Data from the Dietary Habits in Denmark 1995 (29) showed a gender difference in tea and fruit consumption, which explains the differences in flavonoid intake for men and women. Since tea is a major source of flavonoids, the gender differences in tea consumption influence the total flavonoid intake, as well as the intake of other polyphenols that were not included in this study. The mean flavonol (quercetin, kaempferol and myricetin) intake from tea consumption was calculated to $5.2 \mathrm{mg} /$ day and $8.3 \mathrm{mg} /$ day for men and women, respectively, based on a mean tea consumption of $153 \mathrm{~g} /$ day for men and $245 \mathrm{~g} /$ day for women.

Oranges contain high amounts of the flavanones naringin and hesperidin. The mean flavanone intakes for men and women were 5.5 and $8.0 \mathrm{mg} / \mathrm{day}$, respectively, based on a mean orange consumption of $13 \mathrm{~g} /$ day for men and $19 \mathrm{~g} /$ day for women. The gender differences in tea and orange consumption almost explain the difference in mean flavonoid intake of $6 \mathrm{mg}$ /day.

\section{Discussion}

We found the mean Danish flavonol (13.5 $\mathrm{mg} /$ day $)$ and flavanone $(9.3 \mathrm{mg} /$ day $)$

Table 3. Gender distribution of flavonoid intake; mean, median and percentiles.

Table 2. Mean and median values, 10th and 90th percentiles of intake for the most important individual flavonols and flavanones. $n=1837$; men $n=904$ and women $n=933$.

\begin{tabular}{lcccccc}
\hline & $\begin{array}{c}\text { Quercetin } \\
\text { mg/day }\end{array}$ & $\begin{array}{c}\text { Hesperidin } \\
\text { mg/day }\end{array}$ & $\begin{array}{c}\text { Kaempferol } \\
\text { mg/day }\end{array}$ & $\begin{array}{c}\text { Naringenin } \\
\text { mg/day }\end{array}$ & $\begin{array}{c}\text { Myricetin } \\
\text { mg/day }\end{array}$ & $\begin{array}{c}\text { All } \\
\text { mg/day }\end{array}$ \\
\hline Mean & 8.6 & 7.1 & 3.4 & 2.2 & 1.5 & 23 \\
Standard dev. & 6.3 & 12.2 & 5.3 & 4.1 & 1.7 & 22 \\
Median & 6.9 & 1.9 & 1.0 & 0.5 & 0.9 & 16 \\
10th & 2.4 & 0 & 0 & 0 & 0 & 4 \\
90th & 16.9 & 21.6 & 10.8 & 6.8 & 3.8 & 51 \\
\hline
\end{tabular}

\begin{tabular}{lccc}
\hline & $\begin{array}{c}\text { Female } \\
(\mathrm{n}=933) \\
\text { mg/day }\end{array}$ & $\begin{array}{c}\text { Male } \\
(\mathrm{n}=904) \\
\mathrm{mg} / \text { day }\end{array}$ & $\mathrm{p}^{1}$ \\
& & & \\
\hline Mean & 26 & 20 & $<0.001$ \\
Standard dev. & 22 & 20 & \\
Median & 19 & 14 & \\
10th & 5 & 3 & \\
90th & 55 & 44 & \\
& & & \\
\hline
\end{tabular}


intake to be $23 \mathrm{mg} / \mathrm{d}$. This corresponds well with the mean intakes determined in other populations, although the results are not directly comparable since different flavonoid subgroups have been determined in the individual studies. Hertog et al. (25) reported the intake of flavones and flavonols in The Netherlands to be $23 \mathrm{mg} / \mathrm{d}$, not including the determination of flavanones in their study. They found a higher tea consumption contributing $48 \%$ to the mean flavonoid intake, which partly explains the similar mean intake at $23 \mathrm{mg} /$ day in the two countries.

The Danish intakes of flavonols and flavanones are more directly comparable with the results reported for a Bavarian subgroup (63 women, 56 men) of a German national food consumption survey

\section{REFERENCES}

1. Keli SO, Hertog MGL, Feskens EJM, Kromhout D: Dietary flavonoids, antioxidant vitamins, and incidence of stroke: The Zutphen study. Arch Intern Med 1996;156:637-42.

2. Hollman PCH, Katan MB: Absorption, metabolism and health effects of dietary flavonoids in man. Biomed \& Pharmacother 1997;51:305-10.

3. Ness AR, Powles JW: Fruit and vegetables and cardiovascular diseases: a review. Int J Epidemiol 1997;26:1-13.

4. La Vecchia C, Tavani A: Fruit and vegetables, and human cancer. EurJ Cancer Prev 1998;7:3-8.

5. Hertog MGL, Hollman PCH, Venema DP: Optimization of a quantitative HPLC determination of potentially anticarcinogenic flavonoids in vegetables and fruit. J Agric Food Chem 1992; 40:1591-8.

6. Justesen U, Knuthsen P, Leth T: Quantitative analysis of flavonols, flavones, and flavanones in fruit, vegetables and beverages by HPLC with photo-diode array and mass spectrometric detection. J Chromatogr A 1998:799:101-10.

7. Duthie G, Duthie S, Kyle JAM: Plant polyphenols in cancer and heart disease: implication as nutritional antioxidants. Nutr Res Rev 2000; 12:79-106.

8. Zheng W, Doyle TJ, Kushi LH, Sellers TA, Hong CP, Folsom AR: Tea consumption and cancer incidence in a prospective cohort study of postmenopausal women. Am J Epidemiol 1996; 144:175-82.

9. Geleijnse JM, Launer LJ, Hofman A, Pols HAP Witteman JCM: Tea flavonoids may protect against atherosclerosis. The Rotterdam study. Arch Intern Med 1999; 159:2170-4.

10. Hertog MGL, Feskens EJM, Hollman PCH, Katan MB, Kromhout D: Dietary antioxidant flavonoids and risk of coronary heart disease. The Zutphen Elderly Study. Lancet 1993; 342:1007-11.
(28). Their total average intake was $25 \mathrm{mg} /$ day obtained from flavonols $12.0 \mathrm{mg}$ /day and flavanones $13.2 \mathrm{mg} / \mathrm{day}$. The Japanese flavonol intake of $13.8 \mathrm{mg} /$ day reported by Kimira et al. (27) was also in agreement with the present data. No flavanone data were reported in the Japanese study.

We observed gender variations in Danish flavonoid intake, largely due to differences in the consumption of the two major contributors, tea and oranges. Due to a more frequent fruit and tea consumption, women have a higher intake of flavonoids even though they have a lower energy intake (29). Some foods contain high amounts of flavones and flavonols (celery leaves, parsley, cranberries). However, the contributions of these foods to the intake were not calculated in the present study, be-

11. Knekt P, Järvinen R, Reunanen A, Maatela J: Flavonoid intake and coronary mortality in Finland: a cohort study. Br Med J 1996; 312:478-81.

12. Yochum L, Kushi LH, Meyer K, Folsom AR: Dietary flavonoid intake and risk of cardiovascular diseases in postmenopausal women. Am J Epidemiol 1999;149:943-9.

13. Commenges D, Scotet V, Renaud S, JacqminGadda H, Barberger-Gateau P, Dartigues J-F Intake of flavonoids and risk of dementia. Eur J Epidemiol 2000;16:357-61.

14. Hertog MGL, Hollman PCH: Review: Potential health effects of the dietary flavonol quercetin. Eur J Clin Nutr 1996;50:63-71.

15. Vinson JA: Flavonoids in foods as in vitro and in vivo antioxidants. Adv Exp Med Biol 1998;439:151-64.

16. Garcia-Closas R, Gonzales C, Agudo A, Riboli $\mathrm{E}$ : Intake of specific carotenoids and flavonoids and the risk of gastric cancer in Spain. Cancer Causes Control 1999;10:71-5.

17. Robards K, Antolovitch M: Analytical Chemistry of Fruit Bioflavonoids. A Review. Analyst 1997; 122:11R-34R

18. Hollman PCH, de Vries JHM, van Leeuwen SD Mengelers MJB, Katan MB: Absorption of dietary quercetin glycosides and quercetin in healthy ileostomy volunteers. Am J Clin Nutr 1995;62:1276-82.

19. Hollman PCH, van Trijp JMP, Buysman MNCP vd Gaag MS, Mengelers MJB, de Vries JHM Katan MB: Relative bioavailability of the antioxidant flavonoid quercetin from various foods in man. FEBS Letters 1997; 418:152-6.

20. Kühnau J: The flavonoids: a class of semi essential food components: their role in human nutrition. World Rev Nutr Diet 1976;24:117-20.

21. Justesen U, Arrigoni E, Larsen BR, Amadò R: Degradation of flavonoid glycosides and aglycones during in vitro fermentation with human cause the consumption data were not sufficiently specific. Besides, the mean intake of these foods in Denmark is expected to be negligible. Other foods such as potatoes and carrots that are consumed in relatively large amounts in Denmark, do not contain significant levels of the flavonoids included in this study, but contain other natural antioxidants as ascorbic acid, carotenoids, and simple phenols. It will be relevant to consider a total estimate of flavonoids, antioxidant vitamins, simple phenols, and other natural antioxidants to evaluate the health effects of foods.

\section{AKNOWLEDGEMENTS}

The authors warmly thank Mrs. Jytte Børup and Mr. Gunner Rasmussen for technical assistance, and Mrs. Sisse Fagt and Mrs. Margit V. Groth for valuable discussions.

faecal flora. Food Science \& Technol, In press

22. Young JF, Nielsen SE, Haraldsdottir J, Daneshvar B, Lauritsen ST, Knuthsen P, Crozier A, Sandstrøm B, Dragsted LO: Effect of fruit juice intake on urinary quercetin excretion and biomarkers of antioxidant status. Am J Clin Nutr 1999;69:87-94.

23. Aziz AA, Edwards CA, Lean MEJ, Crozier A: Absorption and excretion of conjugated flavonols, including quercetin-4'-O-b-glucoside and isorhamnetin-4'-O- $\beta$-glucoside by human volunteers after the consumption of onions. Free Rad Res 1998;29:257-69.

24. Ameer B, Weintraub RA, Johnson JV, Yost RA, Rouseff RL: Flavanone absorption after naringin, hesperidin, and citrus administration. Clin Pharm Ther 1996;60:34-40.

25. Hertog MGL, Hollman PCH, Katan MB, Kromhout D: Intake of potentially anticarcinogenic flavonoids and their determinants in adults in The Netherlands. Nutr Cancer 1993;20:21-9.

26. Shepherd MJ, Ibe F: Flavonoids in UK Total Diet Samples. MAFF Report No. FD 95/2, UK 1995.

27. Kimira M, Arai Y, Shimoi K, Watanabe S: Japanese intake of flavonoids and isoflavonoids from foods. J Epidemiol 1998;8:168-75.

28. Linseisen J, Radtke J, Wolfram G: Flavonoid intake of adults in a Bavarian subgroup of the national food consumption survey. Z Ernahrungswiss 1997;36:403-12.

29. Andersen NL, Fagt S, Groth MV, Hartkopp HB, Møller A, Ovesen L, Warming DL: Danskernes Kostvaner 1995 (Dietary Habits in Denmark 1995, Summary in English). National Food Agency of Denmark Publication No. 235, Copenhagen, Denmark 1996.

30. Justesen U, Knuthsen P, Leth T: Determination of plant polyphenols in Danish foodstuffs by HPLC-UV and LC-MS detection. Cancer Letters 1997;114:165-7. 